\title{
Successful Implementation of a National Ethiopian Ophthalmology Review Course
}

\author{
Meseret Ejigu ( $\square$ mesifinot@yahoo.com ) \\ Addis Ababa University https://orcid.org/0000-0001-5694-8480 \\ Jacquelyn O'Banion
}

Emory University

\section{Fran Wu}

Emory University

Keri Allen

Emory University

Allison Jarstad

Himalayan Cataract Project

Neda Nikpoor

Himalayan Cataract Project

Matt Oliva

Himalayan Cataract Project

Liknaw Adamu

Himalayan Cataract Project

Barbara Erny

ASCRS Foundation

Aemero Abateneh

Jimma University

Allehone Ayalaew

The Sinksi Clinic

\section{Habtom Hagos}

St Paul's Hospital Millennium Medical College

\section{Fisseha Admassu}

Gonder University

Demoze Delelegn

Hawassa University

\section{Research}


Keywords: Ophthalmology Review Course, Ethiopian ophthalmology residency training, International Council of Ophthalmology exams

Posted Date: December 16th, 2020

DOI: https://doi.org/10.21203/rs.3.rs-127294/v1

License: (1) This work is licensed under a Creative Commons Attribution 4.0 International License. Read Full License 


\section{Abstract}

Background: Development of a national ophthalmology review course for the education of residents and use of a standardized international exam as a metric of resident knowledge and education.

Methods: A 3 day review course for all Ethiopian ophthalmology residents, taught by visiting and local faculty, in preparation for the International Council of Ophthalmology (ICO) exam. The ICO exam serves as an external and standardizing measurement of residency curriculum and preparedness for clinical practice. The course and exam was provided free of cost to residents. Baseline knowledge was assessed with the ICO exam in 2017 and results compared with performance each year after the introduction of the review course.

Results: Over 2 years of implementation, the resident passage rates of the basic sciences and optics and refraction exams increased by $10 \%$ and $28 \%$ and a $15 \%$ improvement in passage rate of the clinical sciences exam. These scores were significantly higher than international averages. Additionally, increasing numbers of residents were able to sit for the advanced exam with a passage rate of $67 \%$ in 2019 compared to the international passage rate of $56 \%$.

Conclusions: The implementation of a national review course is feasible and effective in enhacing the education of ophthalmology residents in Ethiopia. The review course and ICO exam serves as a key metric in the education of Ethiopian residents and their knowledge as it compares to their peers in other countries.

\section{Background}

Since the World Health Organization 1995 paper outlining the burden of blindness and visual impairment and its projected increase, international efforts by Ministries of Health and iNGOs have been focused on the methods of preventing said vision impairment ${ }^{1}$. This realization gave birth to the Vision 2020 The Right to Sight Initiative and later the WHO's Universal Eye Health. Key to both of these movements is the realization that we must improve access to eye care services across the globe. One such proposed method is by increasing the availability of services by training more eye care personnel, and specifically ophthalmologists. The Vision 2020 initiative set a human resource goal based on the burden of blindness by region in an effort to change the projected trend of an increase in blindness by the year 2020 . For subSaharan Africa this goal was set at 4 ophthalmologists per million population. Thus, a certain amount of attention has been paid by national eye care plans and ministries of health to increase the eye care work force by increasing the number of ophthalmologists in training. A study by Palmer et al reviewed this work force development indicator and found that sub-Saharan Africa is nowhere near reaching this goal and many countries will not do so by $2020^{2}$.

Around this time it was noticed that in many parts of the world, particularly in Africa, ophthalmology was taught in the apprenticeship model and had not yet gone through the shift to curriculum based learning that had recently occurred in the U.S. and U.K. Inherent to the apprenticeship model is variation in 
graduate knowledge and skill base that makes understanding the competency level of a recent graduate nearly impossible. With the Accreditation Council of Graduate Medical Education (ACGME) in mind the International Council of Ophthalmology (ICO) began to develop adaptable curricula that kept in mind the outcomes based model of setting goals, expectations, knowledge base, competencies and technical skill ${ }^{3}$. The idea of this curriculum was for it to be open, accessible and adaptable to resident education across the globe ${ }^{4}$. The curriculum is divided into Basic, Standard and Advanced levels each with a knowledge and skills Sect. ${ }^{4,5}$. With this shift in education came the focus of creating measurable competencies and outcomes of ophthalmic training with both summative and formative assessments ${ }^{2,6}$.

With all of this in mind, the Himalayan Cataract Project (HCP), American Society of Cataract and Refractive Surgery Foundation (ASCRS) and Emory University worked with the five ophthalmic training programs in Ethiopia to aide in the education of competent and knowledgeable ophthalmologists based on an international standard. As Ethiopia is one of three countries comprising 2/3rds of Africa's ophthalmologists and yet still has $<2$ ophthalmologists per million population it can arguably be one of the countries in most need of exceptional ophthalmic education and eventually an international center for ophthalmic education ${ }^{7,8}$. With guidance from the above entities the Ethiopian ophthalmic education system has undergone an overhaul with a shift to competency-based curriculum and regular assessments, using the ICO exams as an external measure of success. Here we present the curriculum changes and specifically the ICO review course and its effects on resident knowledge and the ICO passage rate.

\section{Methods}

This study was exempt from review by the Emory Institutional Review Board. With support from Himalayan Cataract Project (HCP) and American Society of Cataract and Refractive Surgery Foundation (ASCRS), initial steps were taken in 2017 to introduce the ICO exam for all ophthalmology residents in Ethiopia in order to get a baseline understanding of their knowledge level with the present curriculum. Subsequently the curriculum from the College of Ophthalmology of Eastern, Central and Southern Africa (COECSA) was adopted by all 5 programs in an effort to standardize ophthalmic education in Ethiopia. This COECSA curriculum is based on the ICO curriculum and outlines specific assessment tools to be used in the evaluation of resident knowledge and technical skill.

Simultaneously, each residency program identified a residency program director who assumed the leadership and accountability for residency education. Program directors participated in workshops and were provided resources to equip them on how to be effective educators. The program directors chaperoned the delivery of the newly instituted curriculum through lectures, reading and assessments.

The 2017 Ethiopian ICO exam results revealed that the gradual process of curriculum implementation alone would not be sufficient to assist residents with standardized ophthalmic exams. Therefore, based off the models of American board review courses, an ICO board exam review course was developed and implemented by the 2018 Emory and HCP Global Ophthalmology fellows. The spring 2018 ICO review 
course was taught primarily by the two global fellows and six local Ethiopian faculty. The 2.5 day comprehensive course emphasized high-yield topics integrating visual science, optics and clinical ophthalmology. Appendix 1 Based on the 2018 post-course feedback, the 2019 global ophthalmology fellows expanded and modified the course further. Six international and 14 Ethiopian lecturers taught for the 2019 course over a 3-day period. Each exam section had its own dedicated time-frame and subcourse. Basic science and optics courses were offered for a full non-overlapping 1.5 days. At the request of the residents, the optics and refraction section incorporated a small group interactive problem-based learning component. Residents who had passed those exams in 2018, participated only in the clinical science sub-course offered over 3 full days. New to the course was a break-out session where two new graduates who had recently passed the Advanced ICO exam, gave test-taking and studying tips based on their personal experiences. Both courses were offered free of cost to the residents thanks to HCP, ASCRS and Emory. Additionally, the cost of travel, housing and exam registration were also provided. The ICO exams continue to be offered to all Ethiopian residents in order to measure impact of curriculum changes.

\section{Results}

In 2017, 40 Ethiopian residents sat for the ICO exam. All took the Basic Science and Optics and Refraction Sect. $77.5 \%$ passed the Basic Science portion and 30\% passed the Optics and Refraction portion. The international rate of passage of the Basic Science section and Optics and Refraction were $59.9 \%$ and $60.5 \%$, respectively. Figure $1 \mathrm{~A}$.

After the first review course in 2018 the Ethiopian results were as follows: 65 residents sat for exams; $86.7 \%$ passed Basic Sciences, $52.9 \%$ passed Optics and Refraction, and $61.1 \%$ passed the Clinical Sciences. Figure 1B. Subsequently, the fall after the first ICO Review Course 4 out of 7 (57.1\%) new Ethiopian ophthalmology graduates, passed the Advanced ICO exam, becoming the first in the country to achieve this academic accolade.

The 2019 ICO course incorporated the modifications of an overall longer course, more practice questions (particularly in Optics and Refraction) and more Ethiopian lecturers who were familiar with resident learning styles and foundational knowledge. In 2019, 71 residents sat for the exams. 87\% passed Visual Sciences (formerly Basic Science), 58\% passed Optics and Refraction and 76\% passed the Clinical exam. This compares to an overall ICO passage rate of $57 \%, 56 \%$, and $70 \%$, respectively. Figure $1 \mathrm{C}$. An additional 8 out of 12 (67\%) young Ethiopian ophthalmologists passed the Advanced exam by Fall 2019, significantly higher than the $56 \%$ passage rate of all those sitting for the advanced exam.

\section{Discussion}

Over the course of 2 years Ethiopia had a 70\% increase in the number of residents sitting for the ICO exams. While the residents have always done better than the international average in Visual Sciences, in all years they drastically improved their scores in Optics and Refraction and in Clinical Sciences after the 
introduction of the review course. By the second review course, Ethiopian resident exam averages were superior to international averages in all ICO exam sections. Through the adoption of a competency-based curriculum and dedicated faculty focused on resident education the knowledge of Ethiopian residents has surpassed that of their international colleagues. Most notable is the academic distinction new graduating Ethiopian ophthalmologists have now achieved ahead of their senior faculty instructors. Additionally, more residents each year, feel increasing confidence to sit for the exams. This confidence has transformed into more Ethiopian graduates, returning to teach for the review course, assuming teaching faculty positions, and pursing international fellowship opportunities.

The World Health Organization and International Agency for the Prevention of Blindness have shifted their focus slightly from the early days of Vision 2020. Instead of focusing on disease eradication and cataract surgery rates solely, attention has shifted to how to provide Universal Eye Health through health systems strengthening. Thus, investing in the education and training of local physicians meets both initiative's goals by providing an increased number of highly trained ophthalmologists.

The Ethiopia program has been successful due to the dedication of the Ethiopian faculty and residents. Implementation of a new curriculum is no easy task and the Ethiopian program directors should be commended for their dedication. Additionally, competency- based learning with its frequent assessments can often feel quite onerous, but the investment of the Ethiopian programs is evident by the increasing number of residents attending the national review course and sitting for the ICO exams.

There were several limitations of our study. Most notably is that it includes a single population and may not be transferrable to all populations. Additionally, the course was offered free of cost to to the residents which likely increased their participation.

\section{Conclusion}

Many have pointed out the importance of investment in human resources as we aim to eliminate avoidable blindness but as several studies have shown, despite the increase in the number of ophthalmologists in low-middle income countries the rate of growth of providers is still outpaced by the growth of the population aged 60 and older. ${ }^{7-9}$ Additionally, as Resnikoff and colleagues point out, "target ratios of ophthalmologists and their density are insufficient indicators as it says nothing about their distribution, scope of work or quality of care" 2 . Thus, investing in the quality of training is key to eliminating vision impairment across the globe. With these key investments in education Ethiopia is well poised to become a leader in ophthalmic education for sub-Saharan Africa.

\section{Abbreviations}

ACGME - American Council of Graduate Medical Education

ASCRS - American Society of Cataract and Refractive Surgery 
HCP - Himalayan Cataract Project

ICO - International Council of Ophthalmology

WHO - World Health Organization

iNGO - International Non-Governmental Organization

\section{Declarations}

Ethical Approval: This study was exempt from ethical approval by the Emory University Institutional Review Board

Consent: Nont Applicable

Availability of data and materials: Data can be requested by contacting the corresponding author Competing Interests: None of the authors have any financial disclosures of conflicts of interests to disclose.

Funding: This work was supported by Himalayan Cataract Project, Emory Eye Center, and the ASCRS Foundation

Authors' Contributions: All authors were involved in the design of the curriculum, the implementation of the conference and writing and review of the manuscript.

Acknnowledgements:

\section{References}

1. Thylefors $B$, Negrel AD, Pararajasegaram R, Dadzie KY. Global data on blindness. Bulletin of the World Health Organization. 1995;73(1):115-21.

2. Resnikoff S, Lansingh VC, Washburn L, et al. Estimated number of ophthalmologists worldwide (International Council of Ophthalmology update): will we meet the needs? Br J Ophthalmol. 2019.

3. Golnik C, Beaver H, Gauba V, et al. Development of a new valid, reliable, and internationally applicable assessment tool of residents' competence in ophthalmic surgery (an American Ophthalmological Society thesis). Transactions of the American Ophthalmological Society. 2013;111:24-33.

4. Tso MO, Goldberg MF, Lee AG, Selvarajah S, Parrish RK 2nd, Zagorski Z. An international strategic plan to preserve and restore vision: four curricula of ophthalmic education. Am J Ophthalmol. 2007;143(5):859-65.

5. Lee AG, Chen Y. Structured curricula and curriculum development in ophthalmology residency. Middle East Afr J Ophthalmol. 2014;21(2):103-8.

6. Spivey BE. Education in ophthalmology over the past 60 years. Surv Ophthalmol. 2017;62(2):241-7. 
7. Palmer JJ, Chinanayi F, Gilbert A, et al. Trends and implications for achieving VISION 2020 human resources for eye health targets in 16 countries of sub-Saharan Africa by the year 2020. Hum Resour Health. 2014;12:45.

8. Palmer JJ, Chinanayi F, Gilbert A, et al. Mapping human resources for eye health in 21 countries of sub-Saharan Africa: current progress towards VISION 2020. Hum Resour Health. 2014;12:44.

9. Resnikoff S, Felch W, Gauthier TM, Spivey B. The number of ophthalmologists in practice and training worldwide: a growing gap despite more than 200,000 practitioners. $\mathrm{Br} \mathrm{J}$ Ophthalmol. 2012;96(6):783-7.

\section{Figures}
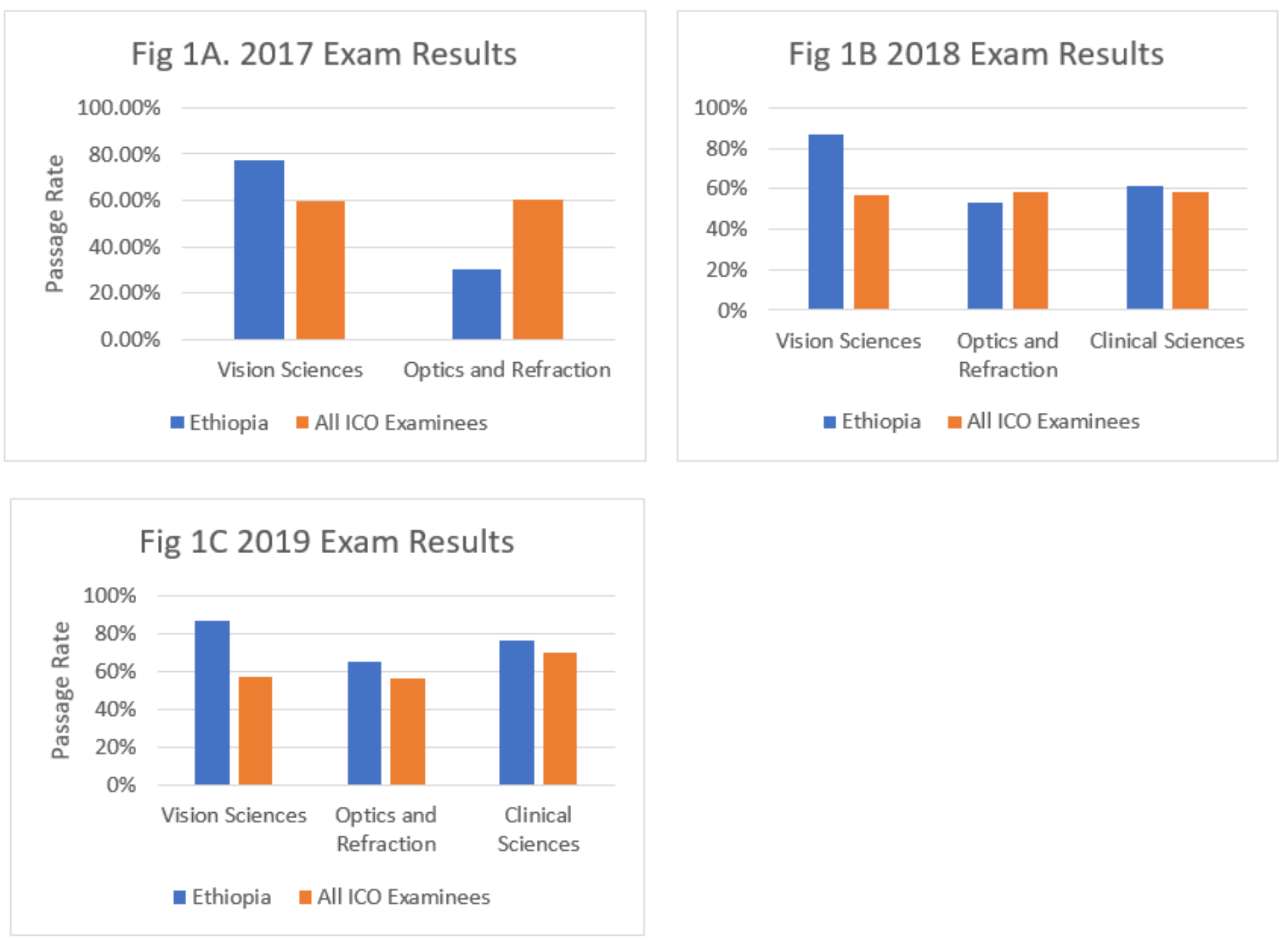

\section{Figure 1}

Exam results from 2017, 2018, 2019 comparing Ethiopian resident results to international averages. 

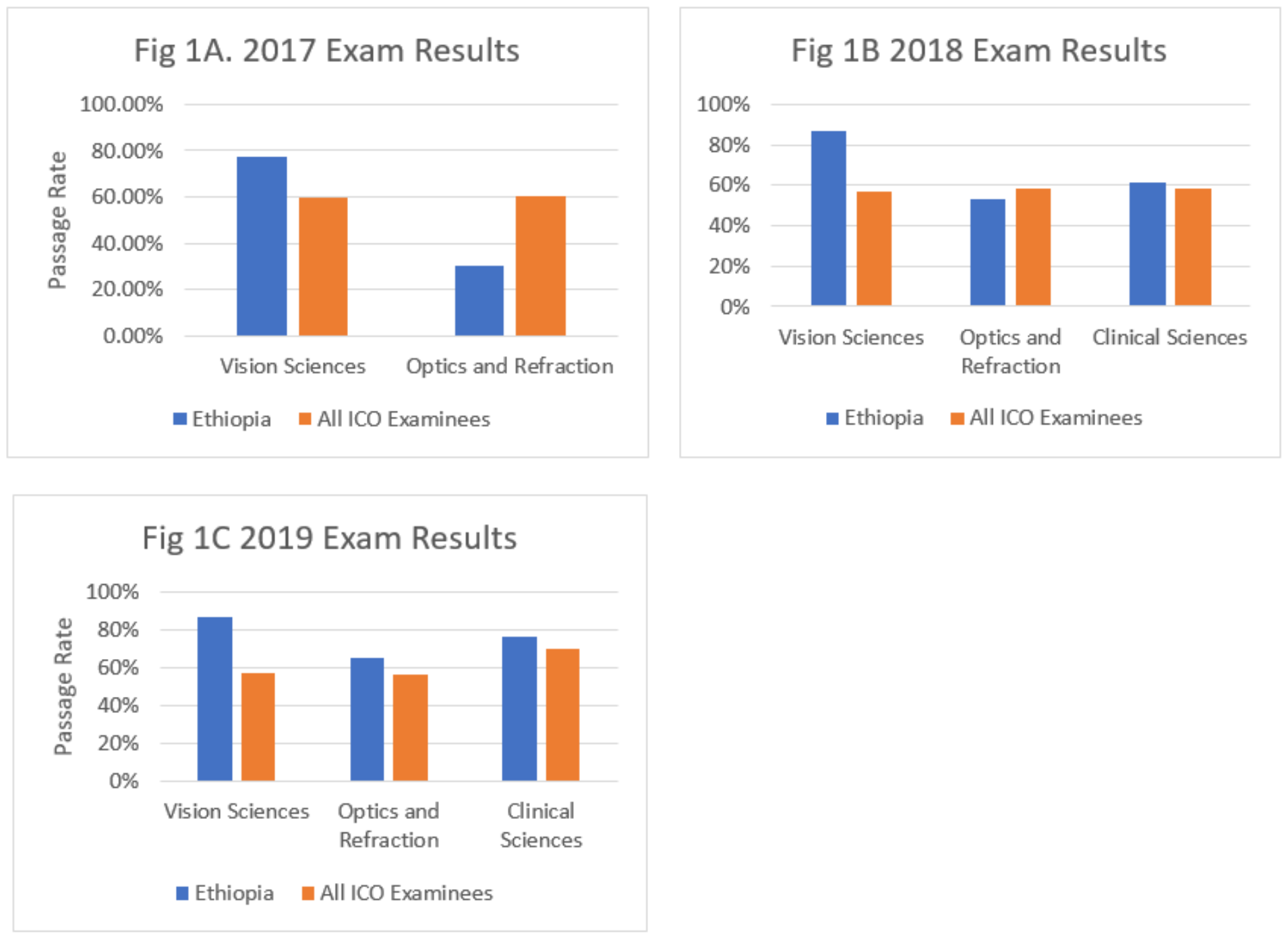

Figure 1

Exam results from 2017, 2018, 2019 comparing Ethiopian resident results to international averages. 

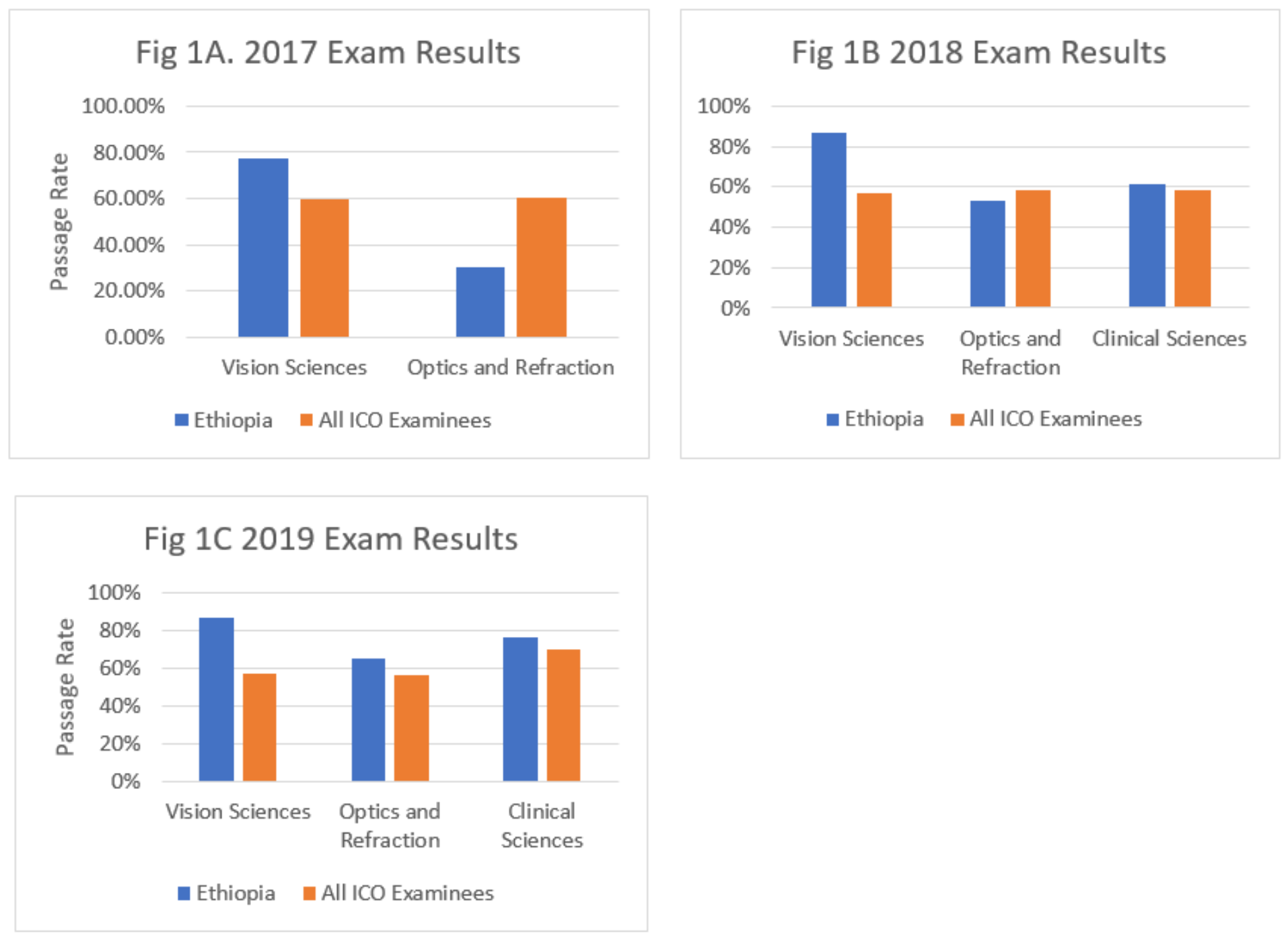

Figure 1

Exam results from 2017, 2018, 2019 comparing Ethiopian resident results to international averages. 

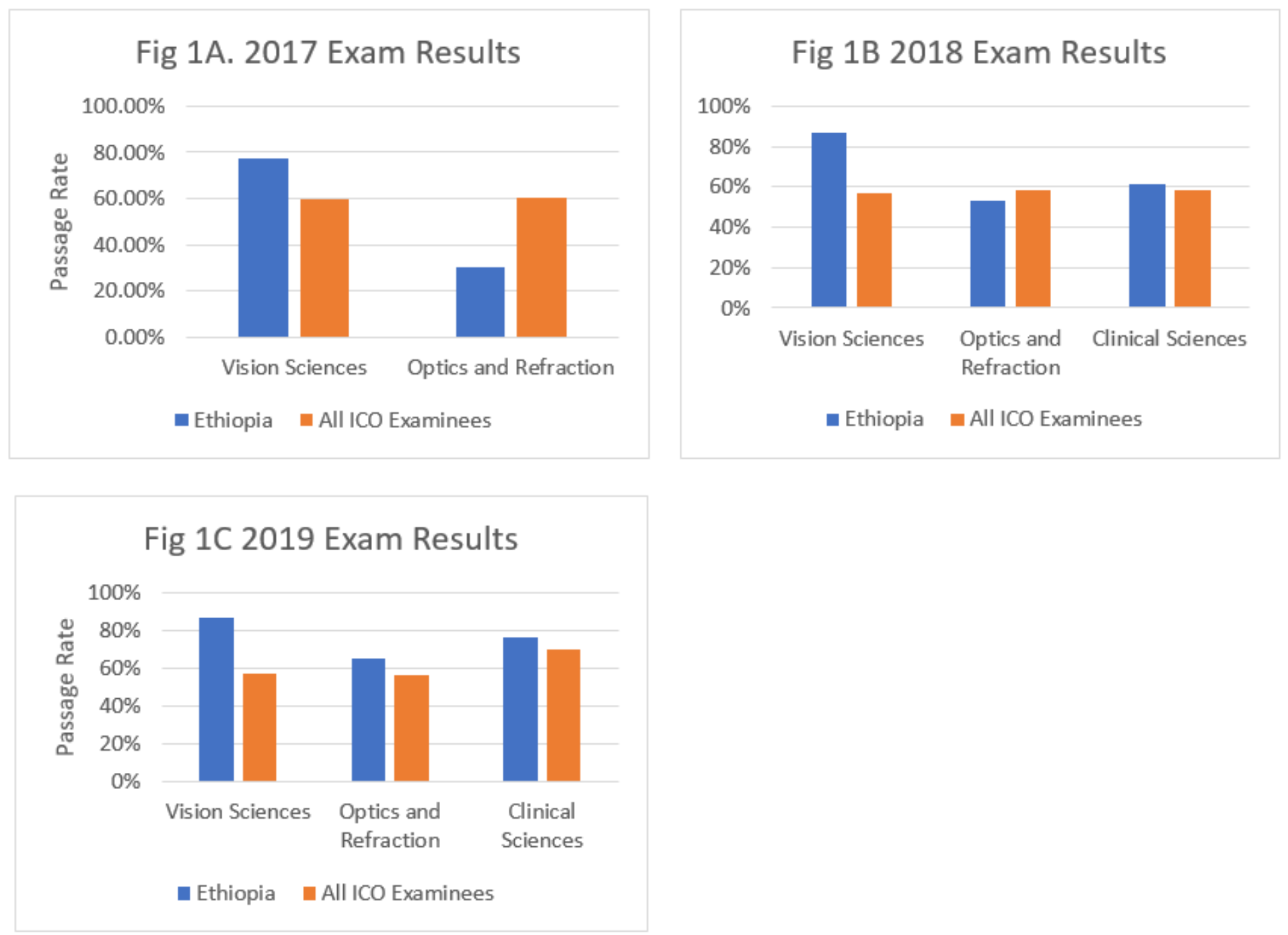

Figure 1

Exam results from 2017, 2018, 2019 comparing Ethiopian resident results to international averages. 

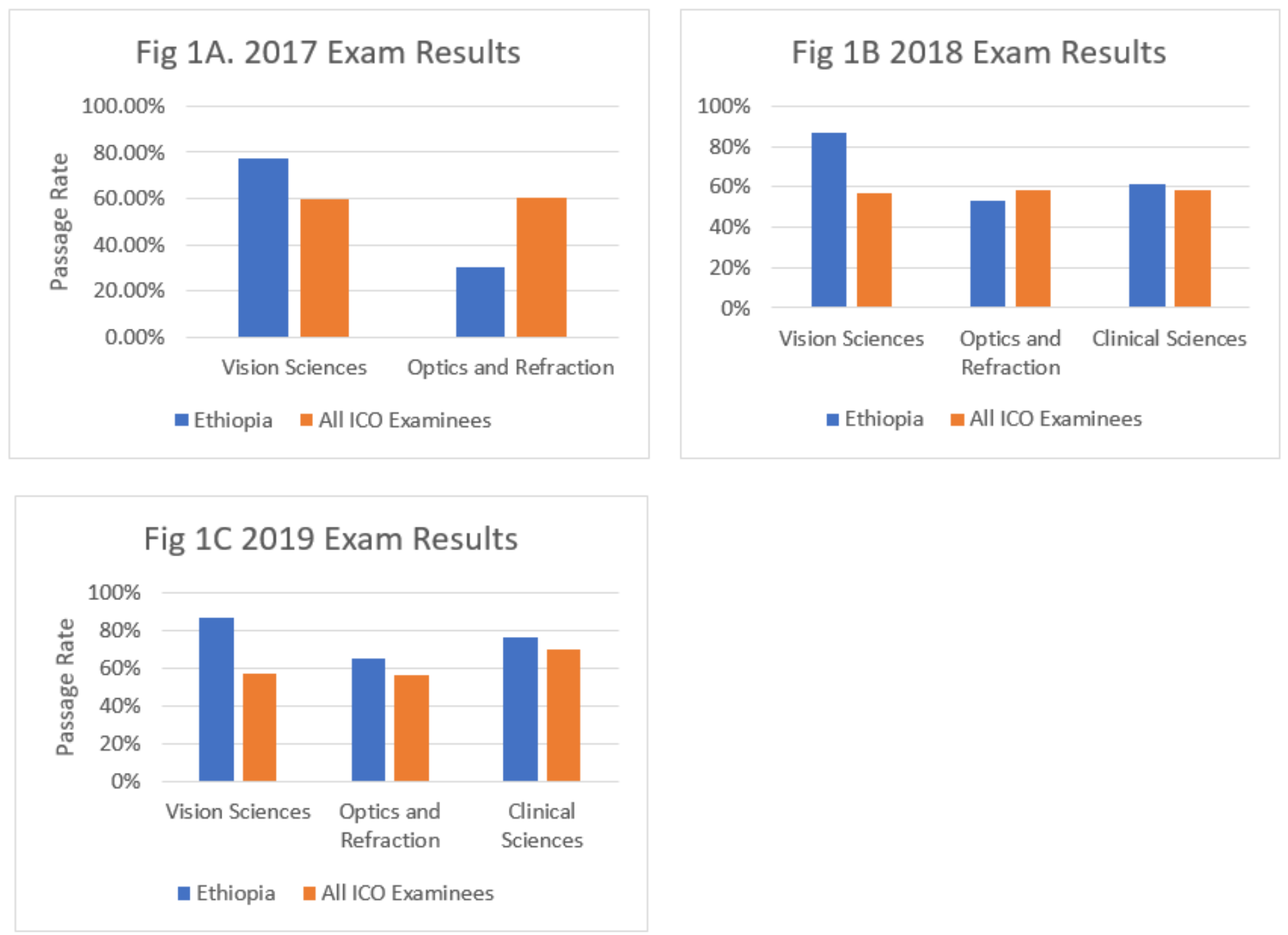

Figure 1

Exam results from 2017, 2018, 2019 comparing Ethiopian resident results to international averages. 

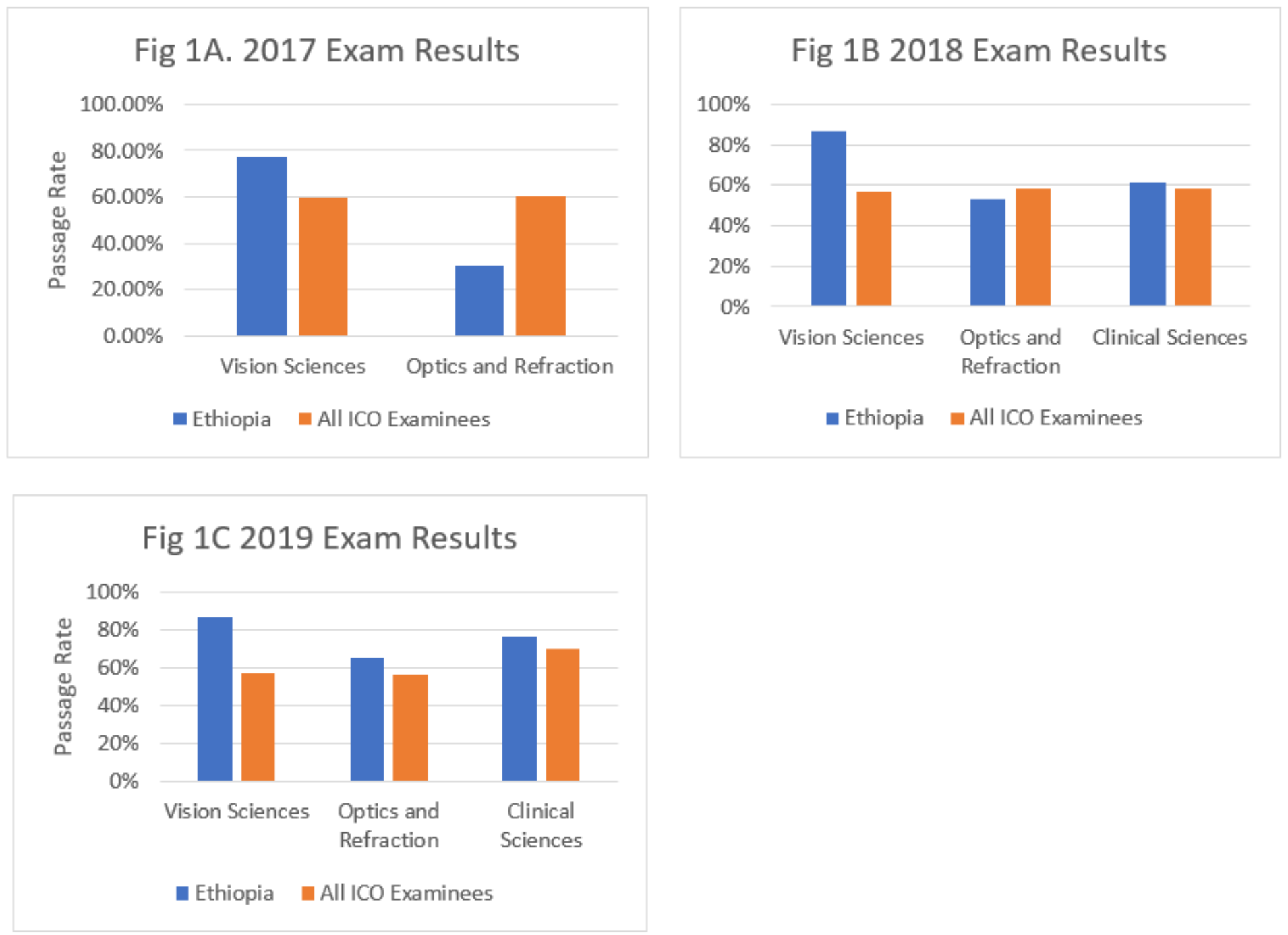

Figure 1

Exam results from 2017, 2018, 2019 comparing Ethiopian resident results to international averages. 

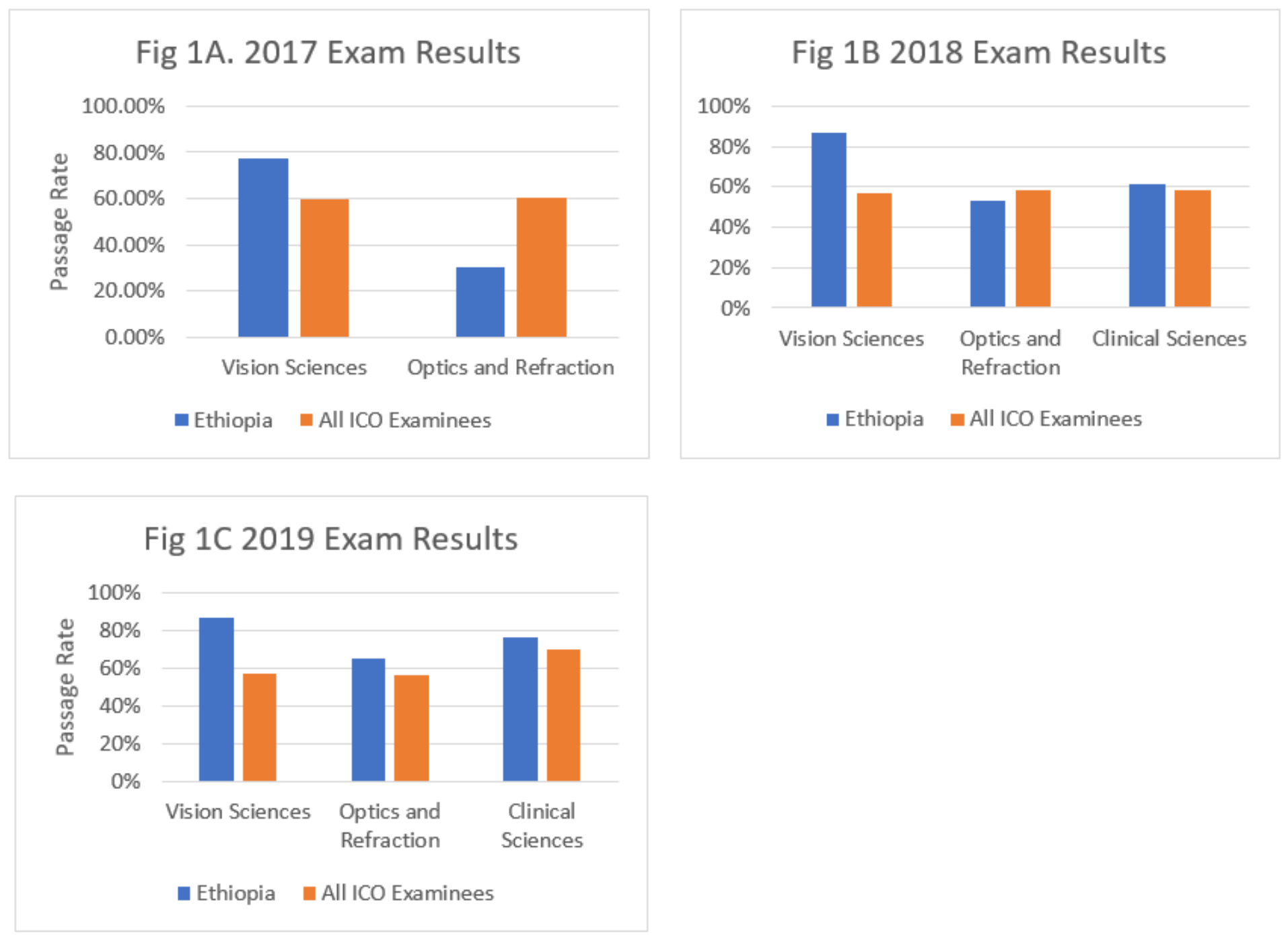

Figure 1

Exam results from 2017, 2018, 2019 comparing Ethiopian resident results to international averages. 

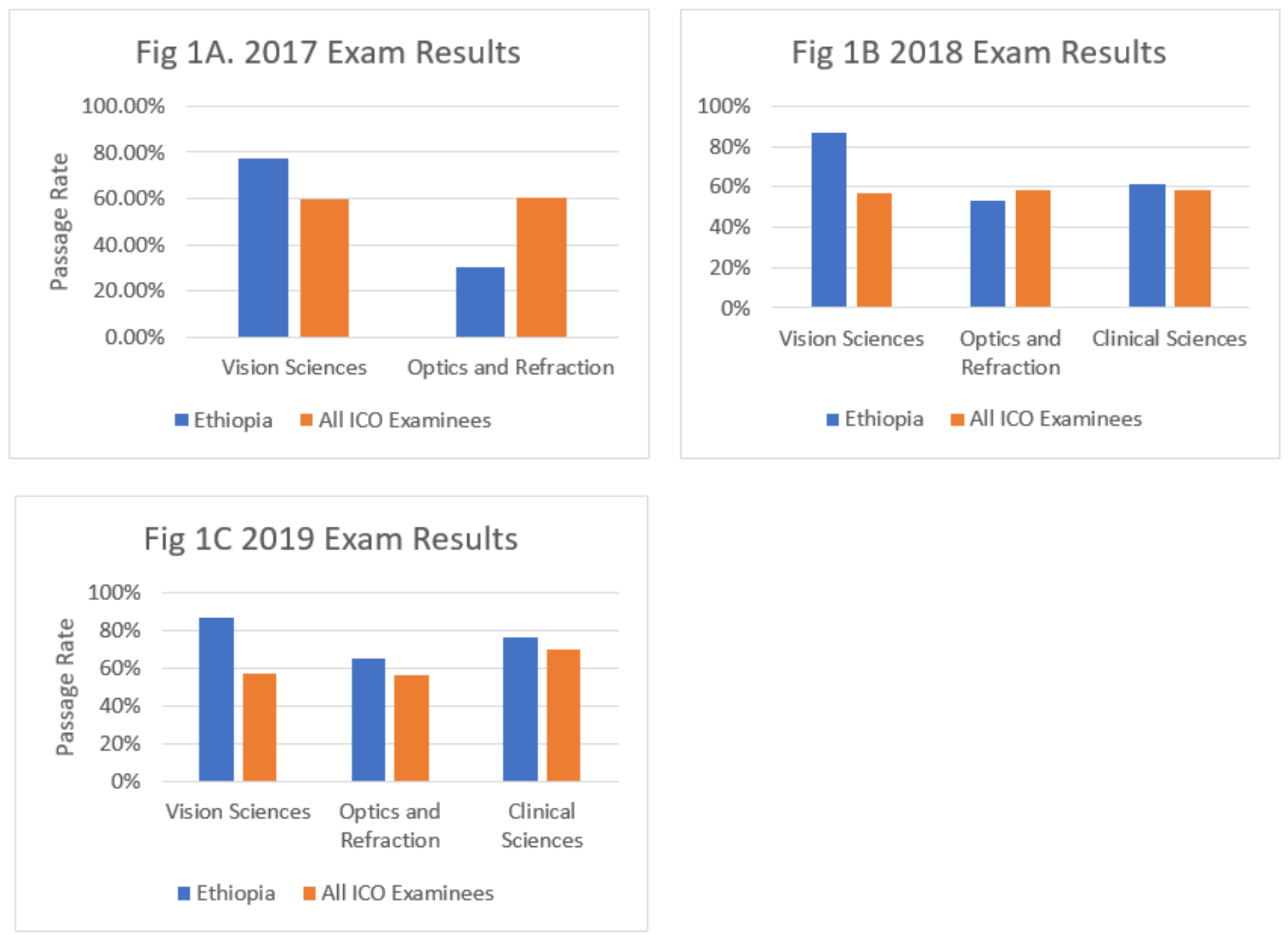

Figure 1

Exam results from 2017, 2018, 2019 comparing Ethiopian resident results to international averages. 

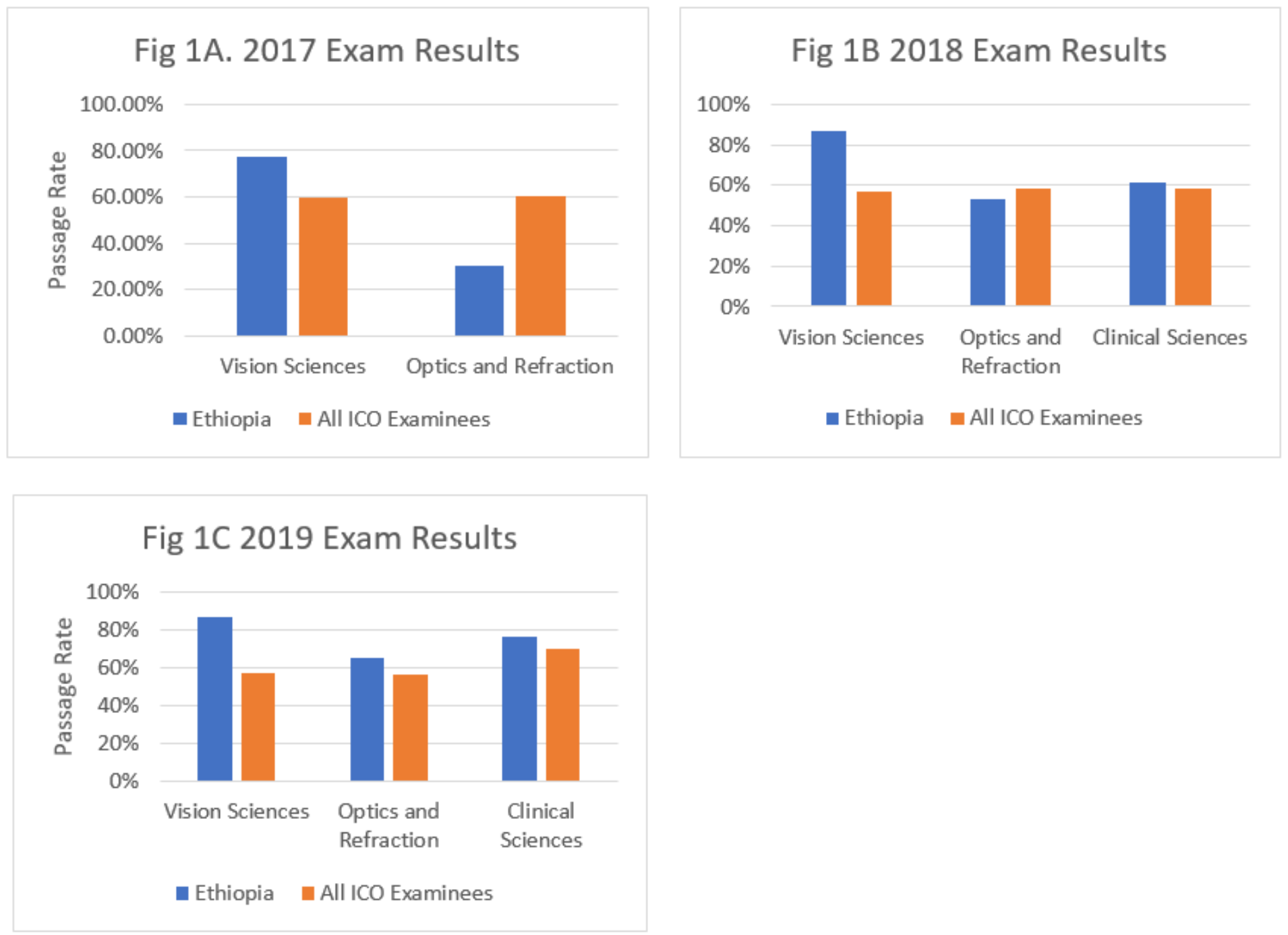

Figure 1

Exam results from 2017, 2018, 2019 comparing Ethiopian resident results to international averages. 